\title{
Motorcyclist rear brake simple perception-response times in rear-end collision situations
}

\begin{abstract}
Objective: The purpose of this study was to determine the baseline motorcycle ridersô perceptionï response times (PRTs) in an expected object braking task and to determine the significant difference between PRTs of older and younger riders.

Methods: Fifty-nine participants sat on their motorcycles in exactly the same way as they would when riding and then they awaited activation of the taillights of the passenger car (parked) in front of them. PRTs of the motorcyclists were transcribed from the camcorder when the riders hit the brakes as quickly as possible following the activation of the car's brake lights.

Results: Results of PRT were calculated by taking the average of both male and female older and younger riders. The study demonstrates that the mean and standard deviation of the motorcycle baseline PRTs are 0.44 and $0.11 \mathrm{~s}$, respectively. Ridersôage and gender were not found to be significant variables for PRT.

Conclusion: The mean of baseline perceptionï reaction time of motorcycle riders is smaller than that of passenger car drivers. If traffic facilities are designed based on passenger car driversô simple perceptionï reaction times where drivers are generally more alert (for example, in traffic signal design), they can provide the required PRT for motorcyclists. This suggests that the utilization of more powerful brake lights on motorcycles could be highly effective for preventing rear-end motorcycle collisions.
\end{abstract}

Keyword: Baseline perception-response time; Motorcyclist behaviour; Rear-end collision 